\title{
Regional Redistribution and Migration
}

\author{
Paolo Manasse *and Christian Schultz ${ }^{\dagger}$
}

13.01 .99

\begin{abstract}
We study a model with free migration between a rich and a poor region. Since there is congestion, the rich region has an incentive to give the poor region a transfer in order to reduce immigration. Faced with free migration, the rich region voluntarily chooses a transfer, which turns out to be equal to that a social planner would choose. Provided migration occurs in equilibrium, this conclusion holds even in the presence of moderate mobility costs. However, large migration costs will lead to suboptimal transfers in the market solution.
\end{abstract}

JEL: H23

Keywords: Migration, regional redistribution, fiscal federalism.

*Department of Economics, Università degli Studi di Milano - Bicocca, Viale Sarca, 202, 20126 Milan, Italy. Ph:+39-2-6448 6594, Fax:+39-2- 6437845 E-mail:paolo.manasse@unimi.it,

${ }^{\dagger}$ Institute of Economics, University of Copenhagen, Studiestraede 6, DK 1455 Copenhagen K, Denmark. Ph: +4535323039, Fax: +4535323000, E-mail:Christian.Schultz@econ.ku.dk 


\section{Introduction}

This paper is concerned with the interplay between interregional redistribution and migration. Citizens of a poor region/country can move to a rich region/country, and benefit economically. Realistically, we assume that immigration is unwelcome in the rich region, there is congestion. Hence the rich region may be willing to transfer some money to the poor one in order to prevent migration. This paper ask the following question: will such voluntary contributions fall short of the social optimum -chosen by a benevolent federal authority - and migration be "excessive"? In other words, do we need to set up federal institutions designed to organize inter-regional/national transfers and to "govern" migration flows?

A quick glance at the public debate on immigration in Europe suggests that this is indeed becoming a hot topic in the political agenda and the public discussion. The Schengen treaty in Europe has recently suppressed customs and border controls between EC members, but it has reinforced demands for tighter controls at the EC boundaries. In France, the recent case of "sans papier", immigrants denied residence and work permits, who were abruptly dislodged from a church in Paris, has raised strong feelings in France and Europe in general. In Italy, the waves of "boat people" from Albania and North Africa has prompted a tighter anti-immigration law, as well as "voluntary" transfers to the governments of Albania and Tunisia, for inducing them to closer collaboration against illegal migration.

While immigration from less developed countries raises the most urgent of problems, with the emergence of xenophobic movements, particularly in France, Italy and Austria, migration within Europe is also likely to have crucial implications for redistribution. It is often argued that the centralization of monetary policy with the single currency requires federal institutions for carrying out redistributive and risk-sharing policies, as it is the case in most federal states. Yet, this view can be questioned, since labor mobility may 
work as well against "asymmetric" shocks.

Finally, in the last two decades regional differences in percapita income and unemployment within countries have risen in Europe, matched by a fall in migration flows, as well by a rise of transfers from rich to poor regions (the case of the North and South Italy is the most obvious example).

The Faeoe Islands, which are a part of Denmark, were subject to a severe economic crisis in the early 90's. This made about one third of the young population move to Denmark mainland. In 1998 the Danish state finally granted the Faroe Islands a huge subsidy in order to stabilize the situation and presumably reverse the wave of migration.

In this context, while many countries are considering to delegate important functions of government to local authorities, the issue of redistribution between rich and poor regions and the role of labor mobility is becoming crucial even at the level of individual countries.

In the paper we reach the following conclusions. Even after allowing for mobility cost, but provided migration costs are moderate, voluntary transfers, decided by the rich regions, and the ensuing migration flows, replicate the social optimum, so that the answer the question above is "no": facilitating labor mobility may be all that is required to achieve optimal redistribution. The case of low mobility costs is likely to be relevant for optimal redistribution among local governments within a country. This conclusion contrasts the traditional public economics view, see e.g. Atkinson and Stiglitz (1980)[1], according to which the task of redistributing among local governments needs to be allocated to a federal government. Our finding that decentralized redistribution is socially optimal is even more attractive in the light of the incentive problems that asymmetric information poses to the design of an efficient federal redistribution scheme (the reader is referred to Bordignon, Manasse and Tabellini (1996)[4] for a model with asymmetric information but with no labor mobility).

The traditional view, however, retains validity when individuals face large mobility 
costs, as may be the case for (illegal) international migrants. In these circumstances we show that the decentralized solution produces insufficient transfers compared to the social optimum.

These conclusions descend from the following logic. In the absence of immigration controls, citizens from the poor region will migrate as long as the economic benefit from the migration exceeds the cost of migration. The rich region cannot directly prevent immigration, but it has the opportunity to give the poor region a transfer, in order to improve the latter's economic conditions, so that fewer people decide to migrate to the rich region. Consider the benchmark case of no mobility costs. Because migration is costless for migrants, the utility from living in the poor and rich regions will be equal after migration has taken place. This is the key to understanding why the voluntary transfer paid by the rich region replicates the social optimum. The rich region cannot hope for being better off than the poor region. Hence, it will try to come up with a transfer which maximizes utility for all individuals in the economy.

When mobility costs are introduced, either there will be no migration at all, if they are very high, or, otherwise, migration will take place until the difference in utility from living in the rich rather than the poor region will equal the mobility cost. In the first case, there is no threat of immigration and the rich has no incentive to give a transfer, while a benevolent federal authority obviously does. Therefore, when the costs of mobility is high the voluntary transfer fall short of the social optimum. When mobility costs are moderate, the rich region will pay just enough to prevent immigration, while the benevolent authority will give more. Here the decentralized market solution is inefficient since it produces suboptimal transfers, but migration is the same. Finally, when migration costs are small, the rich region again acknowledges that it cannot achieve a much higher utility than the poor. Thus the interests of the rich region and the federal authority become aligned and the decentralized solution is again socailly optimal.

An important ingredient of our analysis is that all agents are rational and correctly 
anticipate the effects of the transfer policy. This is chosen by the rich region in the first stage of the game, and affects the subsequent choices of individuals, among which those concerning migration, as well as those of local governments. Since labor is taxed, migration affects fiscal revenues, and thus the local choices of tax rates and local public goods. Our results do not rest on myopia.

Since Tiebout (1956) [21], a large literature has considered the interplay between local taxation, redistribution and migration. Tiebout pointed out that if policies differ among regions, individuals will "vote with their feet". They will settle where the taxation and public goods provision best suit their income and preferences, thus forcing competition and efficiency in local public finance. The literature on fiscal externalities, e.g. Boadway and Flatters (1982)[3], conversely, argued that free mobility across regions is incompatible with a Samuelson provision of public goods. To overcome the fiscal externality induced by free migration, a federal scheme for interregional transfers was called for. In his seminal paper, Myers (1990)[13] questioned this new conventional wisdom, by showing that, when regional governments were allowed to pay a voluntary transfer in order to prevent excessive immigration, free mobility would lead them to choose exactly the same transfer chosen by a benevolent federal social planner. The "market" (Nash) solution was therefore socially optimal, and Tiebout's intuition confirmed. The generality of this result was however questioned by Hercowitz and Pines (1991)[10]. These authors modelled the choice of migration in a dynamic set-up, where individuals choose the country of residence on the basis of shocks to productivity in two jurisdictions. They showed that a positive, albeit small, migration cost was sufficient to destroy the optimality of the market solution: the "rich" region will always choose to transfer to the poor region less than socially optimal. Bucovetsky (1998)[6] showed in a static model that Myers' result holds true also when migration costs are introduced.

Our paper encompasses these results, by presenting a framework where individuals maximize utility from consumption and leisure, local governments explicitly choose dis- 
tortionary (labor) taxes and supply local public goods. In particular, the previous models only considered the negative effects of the immigrants; a fixed regional income is shared by more people. Conversely, in our model immigration increases the pie to be shared, the productivity of the immigrants is higher in the rich region and they contribute to the tax revenue. Our results vindicate Tiebout's (and Myers' and Bucovetsky's) point: moderate migration costs are not sufficient to destroy the optimality of the "market" solution". However, we find that while migration is always optimal in the market solution irrespective of mobility costs, this is not always true for transfers. In particular, provided migration costs are sufficiently high, the rich region takes advantage by reducing the transfer. ${ }^{1}$

The organization of the paper is as follows: Section 2 sets up the model, Sections 3,4 and 5 contain the consumers' and the governments' problems and the analysis of the choice to migrate. Section 6 and 7 discuss the case of no migration cost and derive the decentralized and centralized optimal redistribution schemes. Section 8 shortly considers the case of no commitment. Sections 9 to 12 introduce migration costs into the analysis and discuss the decentralized and centralized solution for this case.

\section{The Model}

Consider two regions, 1 and 2. The regions are identical, except in per capita income. Region 1 is rich, region 2 poor. Each region produces only one good which can be trans-

\footnotetext{
${ }^{1}$ There is another strand of literature concerning migration and redistribution within regions, e.g Musgrave (1969) [14]and Oates (1972)[15], Roemer (1997)[18], Epple and Romer(1991)[9], see also the recent survey of Cremer et al. (1997)[7], Dixit and Londregan (1997) [8] consider the interaction between redistributive politics at central and local levels in a federal system. There is also a vast literature on regional redistribution without mobility, e.g. Persson and Tabellini (1996a, b) [16],[17], and concerning the optimal design of intergovernmental grants, see Bucovetsky et al. (1996) [5], Lockwood (1996)[12], Bordignon, Manasse and Tabellini (1996)[4], and Laffont (1995)[11].
} 
formed into either private or public consumption. The production technology features a constant marginal rate of transformation, so that one unit of labor transforms into one unit of the private/public good. There is no trade among the regions. In the first period each region is equally populated by (within region) identical individuals. We normalize each region's population to one. After period one consumers can migrate freely between the two regions. The number of second period inhabitants in region $i$ is $n_{i}$.

A local government in each region collects distortionary taxes and provides a local public good. All individuals have the same utility function

$$
U(c, x, g, n)=c+V(x)+H(g)-\alpha n
$$

where $c$ is consumption, $x$ leisure time, $g$ the amount of public good, $n$ the population of the region. The functions $V$ and $H$ are twice differentiable with $V_{x}>0, V_{x x}<0, H_{g}>0$ and $H_{g g}<0^{2}$.

Notice that the utility function includes a separate congestion term. Ceteris paribus, an individual's utility decreases with the size of the population of her region. This may be due, for example, to the scarcity of land. It is well known from models of migration, that in stable equilibria with costless migration, it has to be the case that further immigration is unwelcome by the inhabitants of at least one of the regions. To see why this must be the case, consider the following counter example. In an equilibrium with costless migration, the utility from living in each region has to be the same. Assume then that the utility from living in a region increases if further immigration obtains, and this is true for both regions. Then, if by chance an individual moved, his new region would become more pleasant than the other region, attracting further immigration. Hence, for an equilibrium to be stable, immigration has to be unwelcome in at least one region, see Atkinson and Stiglitz (1986).

A simple way of introducing heterogeneity between regions is to assume that the

\footnotetext{
${ }^{2}$ A letter subscript denotes a partial derivative, i.e $V_{x}=\partial V(.) / \partial x$.
} 
effective time endowment of individuals differs in the two locations. An individual living in a generic jurisdiction has the endowment $1+e$, where $e_{1}>e_{2}{ }^{3}$. Region 1 is the more "productive" region. If an individual migrates from location 2 to 1 his endowment increases. The idea is that the infrastructure, capital endowment etc. of region 1 is larger than that of region 2, hence all individuals are more productive when they live in the first region. As a consequence, agents of the rich jurisdiction cannot move with their wealth, since the difference in wealth stems from different infrastructures of the regions. Obviously, this is only one possible assumption, one could also conceive that immigrants into the rich region carried their low productivity with them. We will leave this case for later investigation.

The individuals allocate time between working time, $l$, and leisure, $x$, so that

$$
l+x=1+e
$$

The local government raises a proportional tax on labor income. Since the real wage is one, an individual's budget constraint is

$$
c=(1-t) l
$$

where $t$ is the local tax rate.

In addition to collecting revenue from the income tax, the local government may voluntarily give (or receive) a transfer to (from) the other region. The receiving region uses the proceeds to finance the consumption of the local public good. From the outset we concentrate on the case where only the "rich" region 1 gives a positive transfer. Although, in principle, the "poor" region 2 could choose to give a transfer to the rich region 1 , this will never occur in equilibrium, so we disregard the possibility. The transfer from region 1 to region 2 is $\phi$. Region 1 can only choose a non-negative transfer, it cannot force the other region into paying a transfer.

\footnotetext{
${ }^{3}$ In order to economize in notation, expressions without suffices apply to both regions.
} 
The timing of events is as follows: first the local government in region 1 decides on the transfer to region $2, \phi$. Region 1 is committed to this transfer. Then agents migrate among the regions. Each regional government then chooses its expenditure policy: a level of public goods consumption, $g_{i}$. The tax rate, $t_{i}$, is set in order to fulfill its budget constraint. Given this tax rate, individuals work, pay taxes and enjoy the public and private consumption in their chosen region of residence. The local government tries to maximize the utility of the individuals who lives in the region at the time of the decision. We solve the model backwards.

The regional government budget constraints in the two regions are respectively

$$
g_{1}=n_{1} t_{1} l_{1}-\phi . \text { and } g_{2}=n_{2} t_{2} l_{2}+\phi .
$$

Note that the budget constraint depends on the number of citizens in the last period and on their labor supply. In principle, the government of region 1 may end up in the situation where its proceeds from taxation are not sufficient to cover its transfer expenses because too few people chose to live in the region. In this case the effective transfer may be less than the promised transfer. We will assume that in this case, the transfer has priority over public consumption in region 1 , so that public consumption will be zero. This gives a restriction on the possible transfers $\phi$. Region 1 can only choose levels of $\phi$, which it will be able to honor in the ensuing equilibrium. In equilibrium, where governments have rational expectations of migration, such "default" will not occur. A government will never end up with less revenue than required to pay the transfer to which it has committed.

\section{The Consumer's Problem}

A consumer who has decided to live in a region faces the following problem. Given public goods level, $g$, the population $n$, the tax rate $t$, he seeks to maximize his utility $U(c, x, g, n)$ 
subject to the constraints (1) and (2). The result fulfills the first order condition

$$
V_{x}(1+e-l)=1-t
$$

This gives the labor supply $l(t, e)$, which takes the simple form $l(t, e)=L(t)+e$, due to the quasi-linear utility function. This implies that the tax base of the rich region is $e_{1}-e_{2}$ larger than that of the poor region for the same population and tax rate. Clearly, $L_{t}<0$, so that the supply of labor is decreasing in the tax rate, since the quasi linear utility function eliminates the income effect from the labor supply. ${ }^{4}$ The elasticity of labor supply with respect to $t$ is

$$
\eta(t, e) \equiv-\frac{t l_{t}(t, e)}{l(t, e)}=-\frac{t L_{t}(t)}{L(t)+e}>0
$$

Notice that $\eta(0, e)=0$, and that as the productivity parameter $e$ increases, the labor supply becomes more inelastic, $\eta_{e}(t, e)<0$. Furthermore, it is easy to show that under mild conditions ${ }^{5}$, this elasticity is increasing in the tax rate, $\eta_{t}(t, e)>0$.

The optimal consumption is $(1-t) l(t, e)$. Note that the number of citizens does not affect the individual's choice of consumption and leisure: it only affects his decision of where to live.

Given the tax rate, $t$, the transfer $\phi$, the population of the region $n$, the endowment $e$, we can then write an indirect utility function in one region as,

$$
W(t, \phi, n, e)=(1-t)(L(t)+e)+V(1-L(t))+H(n t(L(t)+e)-\phi)-\alpha n
$$

where the rich region pays a positive transfer $\phi_{1}=\phi>0$ and the poor region receives ("pays" a negative transfer) $\phi_{2}=-\phi$.

\footnotetext{
${ }^{4}$ The function $L(t)$ is defined as $L(t)=1-V_{x}^{-1}(1-t)$, with $L_{t}(t)=1 / V_{x x}<0$

${ }^{5}$ A suffficient (but not necessary) condition for the elasticity to be increasing in the tax rate, $\eta_{t}(t, e)>0$ is that $V_{x x x} \geq 0$, which implies $L_{t t} \leq 0$. This condition, in turn, is sufficient for making the government problem of welfare maximizaton well behaved (see next note).
} 


\section{The Government's Problem}

The local government is benevolent, and seeks to maximize the utility of the residents of its region. Given the number of inhabitants $n$, and the transfer $\phi$, the government solves

$$
\max _{t} W(t, \phi, n, e)
$$

Exploiting the envelope theorem, the first order condition for maximum can be written

$$
n H_{g}((n t L(t)+e)-\phi)=\frac{1}{1-\eta(t, e)} \quad, \quad n>0
$$

This is the Samuelsson rule for the optimal supply of public goods: the sum of marginal rates of substitution between private and public goods (the left hand side) must equal the marginal rate of transformation between public and private goods, as determined by the tax distortion. A higher labor supply elasticity makes taxation more distortionary, and this, for given $n, e$ and $\phi$, lowers the rate at which the private good can be transformed into public good. Hence the optimal supply of $g$ falls. Formally, the last equation determines the optimal tax rate $t=T(\phi, n, e)$, and the level of public goods through the government budget constraint $(3)$. As $\eta(0, e)=0$, we have that the public goods provision is positive if $H_{g}(0)>1$, which we assume. ${ }^{6}$

$$
T_{\phi}(\phi, n, e)=\frac{-W_{t \phi}}{W_{t t}}>0
$$

If a region pays a larger transfer, it needs to raise its tax rate in order to maintain an optimal supply the public good. It is easy to show that the effect of the productivity parameter on the optimal income tax rate, $T_{e}(\phi, n, e)$ is ambiguous because there is a conflict between a substitution and an income effect ${ }^{7}$. Finally, from (8), it is easy to show

\footnotetext{
${ }^{6}$ It is easy to show that a sufficient condition for the second order condition, $W_{t t}<0$, to hold is $L_{t t}<0$ which is always satisfied under our assumptions (see previous note).

${ }^{7}$ When $e$ rises, the labor supply becomes more inelastic, and this calls for a higher optimal tax rate. On the other hand, a larger tax base implies more public goods, whose marginal utility falls. This requires a lower tax rate.
} 
that when there are more members in the community, there is a higher social willingness to pay for the public good: provided the marginal utility of $g$ does not fall too rapidly with revenue, this requires a larger supply of public goods.

\section{Migration}

As migration is assumed to be costless for migrants, a worker settles where the utility is higher. Agents rationally foresee the policies chosen by the governments of the two regions. When an individual decides where to locate, he takes as given the transfer from region 1 to region $2, \phi$. Furthermore, he realizes that he is one point out of a continuum, so he considers as negligible the effect, via $n$, of his own location decision upon the regions' tax rates and public expenditures. He also takes as given the other individuals location choice. Hence, if $n$ individuals decide to locate in region 1, the consumer's utility from living in region 1 will be $W^{1} \equiv W\left(T\left(\phi, n, e_{1}\right), \phi, n, e_{1}\right)$, whereas the utility from locating in region 2 will be $W^{2} \equiv W\left(T\left(-\phi, 2-n, e_{2}\right),-\phi, 2-n, e_{2}\right)$.

In equilibrium with costless migration, two are the possibilities: either one of the regions will be vacated and everybody will choose the other location, or the utility from living in each region must be the same. We will concentrate on interior equilibria, where both regions are inhabited.

In an interior equilibrium, $n^{e}$,we must have

$$
W\left(T\left(\phi, n^{e}, e_{1}\right), \phi, n^{e}, e_{1}\right)=W\left(T\left(-\phi, 2-n^{e}, e_{2}\right),-\phi, 2-n^{e}, e_{2}\right)
$$

In principle there may be more solutions to (10), but if the difference in utility from living in the two regions is monotonically decreasing in $n$, the number of inhabitants in region 1, this cannot be the case, see Figure 1 below. Moreover, in this case the equilibrium will 


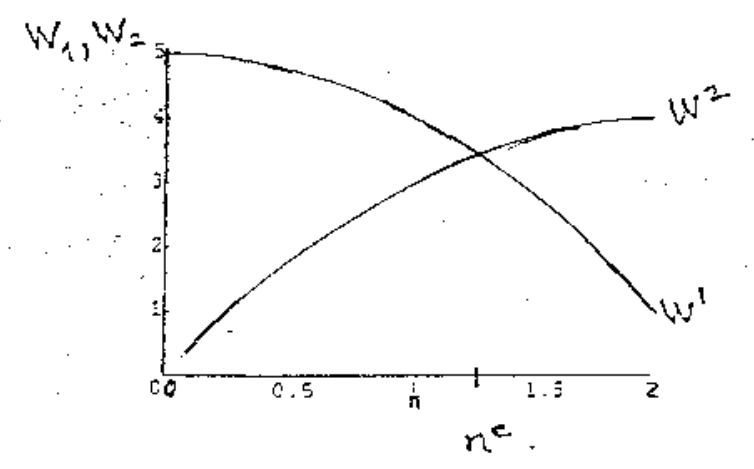

Figlice 1

Figure 1:

be stable. If by chance an individual moved from region 1 to region 2 - so that $n$ falls - utility would increase in region 1 and decrease in region 2, she would therefore like to move back again. Thus, $\frac{d\left(W^{1}-W^{2}\right)}{d n}<0$ is a sufficient condition ensuring that an interior equilibrium will be stable. In the appendix we show that this condition is equivalent to $\frac{H_{g}\left(n t_{1}\left(L\left(t_{1}\right)+e_{1}\right)-\phi\right) t_{1}\left(L\left(t_{1}\right)+e_{1}\right)+H_{g}\left((2-n) t_{2}\left(L\left(t_{2}\right)+e_{2}\right)+\phi\right) t_{2}\left(L\left(t_{2}\right)+e_{2}\right)}{2}<\alpha$,

In the sequel we assume that in an interior equilibrium this condition is satisfied, so that this equilibrium is also unique and stable. In this case, equation (10) defines the second period population of region 1 as a function $N\left(\phi, e_{1}, e_{2}\right)$. Figure 1 illustrates the stable migration equilibrium.

The box describes the allocation of population in the two regions. The utility from living in region 1 is decreasing in $n$, the whereas the utility from living in region 2 is decreasing in $2-n$. In the figure, the equilibrium occurs at $n^{e}>1$, reflecting the assumption that $e_{1}>e_{2}$. From the figure we see that the equilibrium is stable. If, starting from 
$n^{e}$, more individuals move into region 1 and $n$ increases, then region 2 becomes the most attractive region, and people will migrate back until $n^{e}$ is reached.

Under our assumptions, the transfer $\phi$ univoquely determines the distribution of individuals in the two regions $N\left(\phi, e_{1}, e_{2}\right)$ and $2-N\left(\phi, e_{1}, e_{2}\right)$, respectively. If $\phi$, the transfer paid by 1 to 2 , rises, the utility curve for region 2 shifts upwards, while that for region 1 downwards ${ }^{8}$. It is geometrically obvious that in this case $n^{e}$ falls, and we can easily show it algebraically. As before we let $W^{i}$ denote the indirect utility of region $i$. Equation $(10)$, the envelope theorem and the implicit function theorem then yields

$$
N_{\phi}\left(\phi, e_{1}, e_{2}\right)=-\frac{W_{\phi}^{1}+W_{\phi}^{2}}{W_{n}^{1}+W_{n}^{2}}
$$

which we can rewrite, using (6) as

$$
N_{\phi}\left(\phi, e_{1}, e_{2}\right)=\frac{H_{g_{1}}+H_{g_{2}}}{H_{g_{1}} t_{1}\left(L\left(t_{1}\right)+e_{1}\right)-\alpha+H_{g_{2}} t_{2}\left(L\left(t_{2}\right)+e_{2}\right)-\alpha} .
$$

Under (11) we have

$$
N_{\phi}=-\frac{W_{\phi}^{1}+W_{\phi}^{2}}{W_{n}^{1}+W_{n}^{2}}<0
$$

Intuitively, when the transfer from region 1 to region 2 increases, the "marginal" individual who was indifferent between the two locations now prefers location 2 (where he can enjoy more public goods) to region 1 (where he can enjoy less). As a result, individuals will move into 2 until indifference is restored. As the reader may notice, the stability assumption (11) is necessary for having "sensible" comparative static results.

\footnotetext{
${ }^{8}>$ From the envelope theorem, we have that $\frac{d W}{d \phi}=W_{T} T_{\phi}+W_{\phi}=-H_{g}<0$
} 


\section{Federal Transfer}

A useful benchmark for the choice of transfer is the case of social planner, who can choose $\phi$, but cannot determine the location of citizens, nor he is able to choose taxes and public expenditures. This second best solution characterizes the transfer that a benevolent federal government would choose, given that regional authorities have tax and spending powers. This is the natural benchmark to which we can compare the transfer that region 1 would choose non-cooperatively. It must be stressed that we are assuming that the planner/federal government can commit to a lump-sum transfer ${ }^{9}$. In other words, when choosing $\phi$, the federal government correctly anticipates the effects of its decisions on the location choice of individuals as well as upon the regions' fiscal choices. By contrast, the two regions take as given the amount of the transfer, so that the federal scheme is effectively lump-sum. An alternative interpretation of this second best is the following. Before they know the realization of a (positive or negative) productivity shock, two regions, which are ex-ante identical and equally likely to be "rich" or "poor", sign a contract under "a veil of ignorance". The contract specifies the amount that the ex-post rich region must pay to the poor. In this interpretation the assumption of commitment means that the optimal contract cannot be renegotiated, so that when a region finds herself rich, she cannot renege on the agreed transfer. The second best transfer is the solution to

$$
\begin{aligned}
& \max _{\phi} N(.) W^{1}+(2-N(.)) W^{2} \equiv \\
& N\left(\phi, e_{1}, e_{2}\right) W\left(T\left(\phi, N\left(\phi, e_{1}, e_{2}\right), \phi, N\left(\phi, e_{1}, e_{2}\right), e_{1}\right)\right. \\
& +\left(2-N\left(\phi, e_{1}, e_{2}\right)\right) W\left(\left(T\left(-\phi, 2-N\left(\phi, e_{1}, e_{2}\right),-\phi, 2-N\left(\phi, e_{1}, e_{2}\right), e_{2}\right)\right.\right.
\end{aligned}
$$

Let the optimal transfer and the equilibrium population in this second best be denoted

\footnotetext{
${ }^{9}$ Problems of lack of commitment in redistribution are discussed in the next section, cf also Bordignon, Manasse Tabellini (1996) [4]and Bottazzi and Manasse(1998)[2]
} 
by $\phi^{*}, n^{*}$.

We have the following

Lemma $1 \phi^{*}, n^{*}$ are jointly determined by the indifference condition (10) together with the requirement that the marginal rate of substitution between transfer and immigration is the same for the two districts.

$$
\frac{W_{\phi}^{1}}{W_{n}^{1}}=\frac{W_{\phi}^{2}}{W_{n}^{2}}
$$

Proof. see Appendix

\section{$7 \quad$ Voluntary Transfer by the Rich Region.}

Now consider the following set up. Before migration takes place, the government of region 1 decides on the transfer to region 2. The local government is committed to the transfer. It rationally foresees the migration consequences of its choice and it can figure out the ensuing equilibrium. The local government in region 1 is only allowed to choose a transfer which it is eventually able to pay. It tries to maximize the utility of those living in region 1 in the first period. In principle, its citizens may choose to move to the other region in the next period. But as the utility from living in the two districts will be the same as indicated by (10), the government in region 1 maximizes the utility of its citizens if it maximizes the utility of a citizen which plans to stay. Even though the government can commit to a transfer, $\phi$, it cannot commit itself to its subsequent choice of tax and expenditure policy. This assumption reflects the idea that inter-regional (national) transfers are longrun decisions that need domestic consensus, and cannot be modified as easily as the choice of tax rates or spending. The government's problem is

$$
\max _{\phi} W\left(T\left(\phi, N\left(\phi, e_{1}, e_{2}\right), e_{1}\right), \phi, N\left(\phi, e_{1}, e_{2}\right), e_{1}\right)
$$

Now let $\phi^{R}, n^{R}$ denote the solution to this problem. Next we show that 
Theorem 1 The optimal choice of transfer from the point of view of region 1 and the ensuing allocation of individuals coincide with the second best federalist solution: $\phi^{R}=$ $\phi^{*}, n^{R}=n^{*}$.

Proof. Look at the planner's problem (15), using (10) we get that this problem is equivalent to the problem

$$
\max _{\phi} 2 W\left(T\left(\phi, N\left(\phi, e_{1}, e_{2}\right), e_{1}\right), \phi, N\left(\phi, e_{1}, e_{2}\right), e_{1}\right)
$$

which of course has the same solution as (18).

Corollary 1 It follows that tax rates and the level of spending will also be the same as in the second best.

Faced with the threat of immigration, region 1 voluntarily chooses the same transfer as the planner. The intuitive reason is that migration equalizes utility in the two regions. Region 1 cannot hope to get higher utility than that of region 2 , since it is forced to take the consequences of migration into account. But this means that the region acts as if it were maximizing the joint federal utility, which is exactly what the planner does. This is essentially Myers' (1990) result.

This conclusion rests on the ability of region 1 to commit to the transfer. In the model, after migration has taken place, region 1 would rather not pay the transfer. However, we do not find this is an important limitation on the result. Migration and transfers are recurrent events in the real world. So one can allude to repeated game effects. If region 1 reneges on its promise to give the transfer, this will trigger migration.

\subsection{No Commitment}

Here we make one simple point. Region 1's ability to commit to a positive transfer improves welfare in both regions. Consider the case where, despite free labor mobility, no 
transfer is paid in equilibrium because region 1 lacks commitment in deciding $\phi$. Suppose the transfer decision is not credible, (the transfer is chosen by 1 after the choice of location has been made). Once individuals have moved, it is ex-post optimal for region 1 to set $\phi=0$. As potential migrants anticipate this outcome, migration is excessive and federal welfare is reduced. Remember that, with free mobility and commitment, region 1 voluntarily chooses a positive transfer, although it could choose to give no transfer. This is because region 1 gains from the transfer, by reducing congestion (region 2 also gains from the transfer). Committing to a positive transfer is Pareto improving.

\section{Costly Migration}

In this section we make a leap toward "realism" and investigate how our results change if we introduce a cost of migration. Let $c$ be the utility loss associated with moving from one region to the other. In this case an agent only decides to move if the utility gain exceeds $c$. Therefore, utility from living in a region can at most exceed the utility from living in the other region by $c$. If $W^{1}>W^{2}$, then individuals will move from 2 to 1 until $W^{1}-c \leq W^{2}$. If, conversely, $W^{1}<W^{2}$, individuals will move from 1 to 2 until $W^{1} \geq W^{2}-c$.

Finally, when $W^{1}=W^{2}$, no mobility occurs. Putting these conditions together, we find that our free migration condition (10) is replaced by

$$
W^{2}-c \leq W^{1} \leq W^{2}+c
$$

In our model, the rich region 1 always is the attractive region, so $W^{2} \leq W^{1}$, and only the rightward inequality is binding. The relevant condition reduces to

$$
W^{1}-c \leq W^{2}
$$




\subsection{Federal Transfer with Mobility Costs}

In principle, the planner could use the transfer either to allow or to prevent migration. He may want to choose a "large" transfer, for preventing migration ${ }^{10}$, because, in addition to the congestion effects, the planner internalizes the mobility costs suffered by migrants. This is more likely the larger is $c$ and the smaller the distortionary effects induced by higher taxes in region 1. Alternatively, the planner may choose a "small" transfer, and allow migration, in order to reap the positive productivity and output effects. This is more likely the smaller the mobility costs, $c$, and the larger the distortionary effects of the transfer on the tax rate chosen by region 1 .

\section{2 "High" Mobility Cost}

Consider the case where mobility costs are high (relatively to the difference in endowments) so that an individual is better off staying in the poor region rather than moving to region 1 , even when no transfer is paid, that is the condition

$$
W^{1}-c \equiv W\left(T\left(0,1, e_{1}\right), 0,1, e_{1}\right)-c \leq W\left(T\left(0,1, e_{2}\right), 0,1, e_{2}\right) \equiv W^{2}
$$

is satisfied. The previous expression implicitly defines a threshold level for the mobility $\operatorname{cost}$

$$
\bar{c} \equiv W\left(T\left(0,1, e_{1}\right), 0,1, e_{1}\right)-W\left(T\left(0,1, e_{2}\right), 0,1, e_{2}\right)
$$

such that when $c \geq \bar{c}$ no one moves and $n=1$. Note that when mobility cost exceed this critical value, there is no migration irrespective of the value of the transfer.

For $c \geq \bar{c}$, the planner's problem is

$$
\max _{\phi} W^{1}+W^{2}=W\left(T\left(\phi, 1, e_{1}\right), \phi, 1, e_{1}\right)+W\left(T\left(-\phi, 1, e_{2}\right),-\phi, 1, e_{2}\right)
$$

\footnotetext{
${ }^{10}$ Note that he will never choose a value of $\phi$ so induce emigration into region 2, since this would reduce total federal output, consumption and welfare.
} 
The first order condition is

$$
W_{\phi}^{1}=W_{\phi}^{2}
$$

or

$$
H_{g}\left(t_{1}\left(L\left(t_{1}\right)+e_{1}\right)-\phi\right)=H_{g}\left(t_{2}\left(L\left(t_{2}\right)+e_{2}\right)+\phi\right)
$$

The planner equalizes the marginal utility of public goods across regions. This requires a transfer that enables each region to supply the same level of public goods, $g_{1}=g_{2}$. Since the marginal utility from private consumption is constant, the planner does not necessarily equalize welfare in the two districts. In order to equate public consumption the optimal lump-sum transfer is given by

$$
\phi_{c}^{*}=\frac{t_{1}\left(L\left(t_{1}\right)+e_{1}\right)-t_{2}\left(L\left(t_{2}\right)+e_{2}\right)}{2}>0
$$

so that the difference between revenues from the income tax is equally split in two ${ }^{11}$.

Suppose that the transfer $\phi_{c}^{*}$ in $(24)$ is paid to the poor region. We know that this transfer does not necessarily equate utility among regions. When $c \geq \bar{c}$ no migration occurs whatever the transfer. But as soon as we start lowering the migration cost, migration may occur. It is easy to see that no migration still takes place provided the cost exceeds a critical value, $c \geq \tilde{c}$. This value is implicitly defined by the indifference condition

$$
W\left(T\left(\phi_{c}^{*}, 1, e_{1}\right), \phi_{c}^{*}, 1, e_{1}\right)-\tilde{c}=W\left(T\left(-\phi_{c}^{*}, 1, e_{2}\right),-\phi_{c}^{*}, 1, e_{2}\right)
$$

Intuitively, $\tilde{c}$ is the mobility cost which is just sufficient to prevent migration when the optimal transfer, $\phi_{c}^{*}$, is paid. Clearly this value is smaller than $\bar{c}$, the mobility cost that just starves off migration when no transfer at all is paid, $\tilde{c}<\bar{c}$ (compare (22) and (25)). We have discovered that, provided the migration cost exceeds the threshold , $c \geq \tilde{c}$, the central planner optimally chooses a transfer $\phi_{c}^{*}$ defined in (24) and avoids migration, $N^{c}\left(\phi_{c}^{*}, e_{1} e_{2}\right)=1$.

\footnotetext{
${ }^{11}$ This formula is exactly as that derived by Bordignon, Manasse and Tabellini (1996)[4], under the assumption of no mobility.
} 


\section{3 "Low" Mobility Costs}

Let us now consider the case where $c<\tilde{c}$. Now migration does occur even if the transfer $\phi_{c}^{*}$ is paid, hence the mobility constraint is binding and we have that

$$
W^{2}=W^{1}-c
$$

is restored. By implicit differentiation, we can calculate the effect of the transfer on region 1's population, i.e. the partial derivative $N_{\phi}^{c}\left(\phi, e_{1}, e_{2}\right)$. Compare the mobility conditions with zero or positive migration costs, (10) and (26). It is clear that $N_{\phi}^{c}=N_{\phi}$ as given by (12). Thus when the mobility constraint is binding, mobility costs do not affect the decision of the marginal emigrant ${ }^{12}$.

The planner internalizes the mobility costs, so he solves the problem

$$
\begin{aligned}
& \max _{\phi} n W^{1}+(2-n) W^{2}-(n-1) c= \\
= & N^{c}(\phi, .) W\left(T_{1}(.), N^{c}(\phi, .), \phi, e_{1}\right)+ \\
& +\left(2-N^{c}(\phi, .)\right) W\left(T_{2}(.), 2-N^{c}(\phi, .),-\phi, e_{2}\right)-\left(N^{c}(\phi, .)-1\right) c
\end{aligned}
$$

Using (26) this problem reduces to

$$
\max _{\phi} n W^{1}+(2-n)\left(W^{1}-c\right)-(n-1) c
$$

or

$$
\max _{\phi} 2 W^{1}-c
$$

Clearly, this has the same solution as region 1 would choose. Let $\Phi^{*}(c)$ be the planners optimal transfer at mobility cost $c$ and $\Phi^{R}(c)$ region 1's optimal transfer. It is by now straightforward to show that the first order condition for the transfer satisfies

$$
\frac{W_{\phi}^{1}}{W_{n}^{1}}=\frac{W_{\phi}^{2}}{W_{n}^{2}} .
$$

\footnotetext{
${ }^{12}$ Note that at the value $\phi$ for which $N^{c}\left(\phi, e_{1}, e_{2}\right)=1$ and $W^{1}+c=W^{2}, N^{c}($.$) is non-differentiable.$ Its right derivative equals $N_{\phi}$, and its left derivative equals 0 .
} 


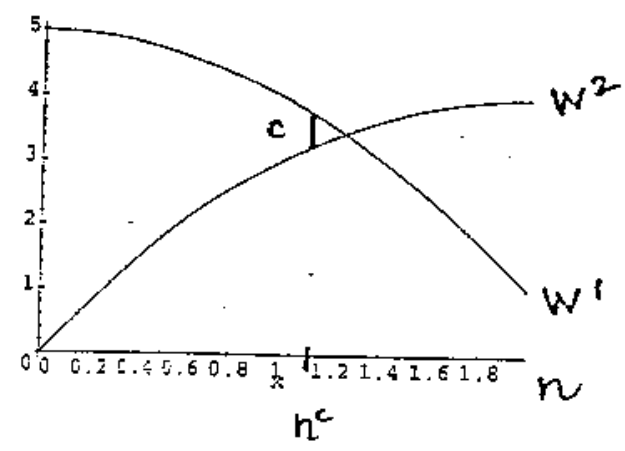

Figure 2:

Figure 2:

Which is the same as the condition obtained with zero moving costs. The planner (and the rich region 1) chooses a transfer such that the marginal rate of substitution between transfer (public goods) and immigration is the same for the two districts. However, notice that $\phi$ and $n$ are determined jointly by (28) and (26), so for a given $n$, the optimal transfer $\Phi^{*}(c)$ is lower than without moving costs. It follows directly from (26) that the optimal transfer is decreasing in the mobility cost, i.e. $\Phi_{c}^{*}(c)<0$, and $\Phi^{*}(0)=\phi^{*}$. Similarly, for a given transfer, the migration is smaller with mobility cost than without. Intuitively, the mobility costs makes more costly for the planner to let people into the more productive region.

The solution is illustrated in Figure 2. In the absence of migration costs the equilibrium population of region 1 would be $n>1$. With moving costs, illustrated by the vertical line, the equilibrium population is only $n^{c}<n$ and utility from living in region 1 exceed utility from living in region 2 by $c$. The solution clearly demonstrates that region 1 benefits from mobility costs. 
To summarize the discussion

Theorem 2 When the mobility cost is "low", $c \leq \tilde{c}$, with c defined implicitly in (25), and migration takes place in equilibrium, $N^{c}\left(\Phi^{*}(c), e_{1}, e_{2}\right)>1$, the transfer voluntarily chosen by region $1, \Phi^{R}(c)$, is equal to the second best solution, $\Phi^{*}(c)$.

Thus we see that if it is optimal for the planner to allow migration, region 1 voluntary chooses the same level of transfer that the planner would choose, $\Phi^{R}(c)=\Phi^{*}(c)$. This may seem surprising. The point is that whenever it is too costly to prevent migration, the planner knows that it cannot influence the difference in welfare between living in the two regions, given by the mobility cost $c$. In this case he and the rich district have the same objective, maximize utility subject to this constraint. Therefore the solution is the same. Hence if migration occurs in the second best, the market produces the same solution as the planner, even in the presence of migration costs.

\section{Voluntary Transfer with Mobility Costs}

We already know the choice of $\phi^{R}$ by region 1 when mobility costs are low, i.e. less than $\tilde{c}$. We now characterize the transfer that region 1 would choose for high $(c \geq \bar{c})$ and moderately high mobility costs $(\tilde{c}<c<\bar{c})$. Evidently, the only reason region 1 voluntary pays a transfer is to reduce immigration.

\section{1 "High" Mobility Cost}

Consider the case where mobility costs are so high that an individual is better off staying in the poor region rather than moving to region 1 , even when no transfer is paid, that is $c \geq \bar{c}$. A positive transfer to the poor region would only raise welfare in 2 and reduce 
welfare in 1 , thus making migration even less desirable. Clearly, in this case the optimal transfer from region's 1 point of view is $\phi_{c}^{R}=0$.

\subsection{Moderate Mobility Cost}

We now consider the case when $\tilde{c}<c<\bar{c}$. From the previous sections we know that when $c=\tilde{c}, \Phi^{R}(\tilde{c})=\Phi^{*}(\tilde{c})$, and furthermore, by the definition of $\tilde{c}$, we have that $\left.N^{c}\left(\Phi^{R}(\tilde{c}), e_{1}, e_{2}\right)\right)=1$. This means that region 1 is willing to give a transfer that is sufficient to starve off migration at $\tilde{c}$. Clearly, when $c$ is higher than $\tilde{c}$ a even smaller transfer is sufficient to starve off immigration. A fortiori the rich region must be willing to pay such a smaller transfer. Thus the rich region chooses the smallest transfer which prevents migration. We conclude that for $\tilde{c}<c<\bar{c}, \Phi^{R}(c)<\Phi^{*}(c)$, while migration is zero both in the federal and the market case.

\section{Comparing the Market and Planner Solutions}

In Figure 3 we show the transfers chosen by the planner and the rich region 1 . For low mobility costs the two coincide. As the mobility costs rises region 1 is able to prevent migration even with lower transfer, while the planner internalizes the benefits of redistri-

bution. For very high mobility cost the voluntary transfer falls to zero. Figure 4 shows the corresponding equilibrium population of region 1 in the two regimes. When the cost is above $\tilde{c}$, there is no migration in both regimes but for different reasons. The planner redistributes, so an individual is better off staying in welfare in region 2 than migrating. Region 1, on the other hand, just gives enough to prevent migration. For lower mobility costs mobility occurs. Since the tranfers in the two regimes coincide, so does migration. The lower the cost, the more migration. 


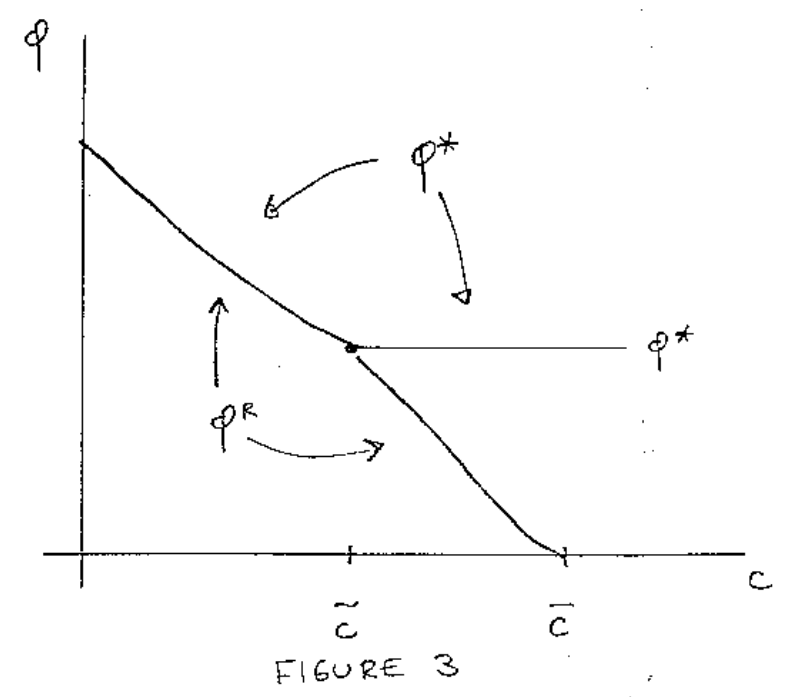

Figure 3:

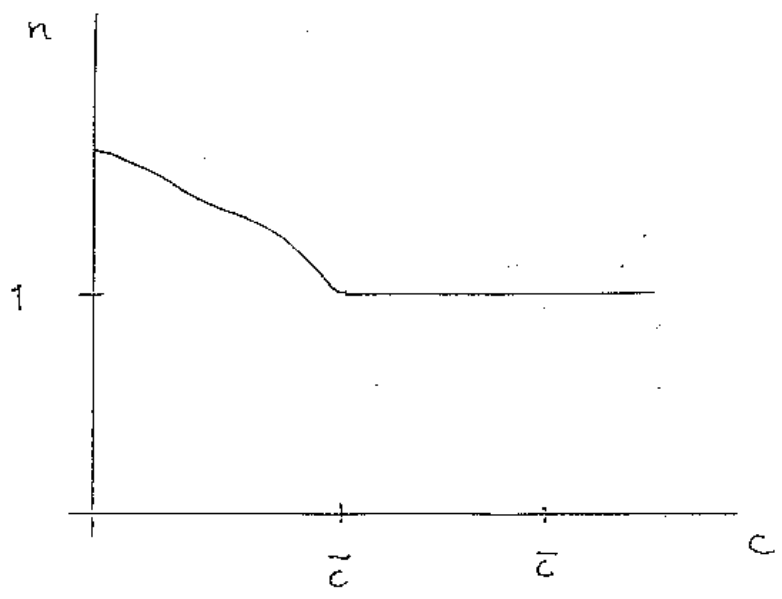

FIGURE 4

Figure 4: 


\section{Conclusions}

This paper has asked a simple question: do we need to set up federal institutions designed to organize inter-national/regional transfers and to implement redistributive policies? Provided migration costs are not prohibitive relative to the differences in percapita income- the answer is no: voluntary (decentralized) transfers replicate the social optimum, so that facilitating labor mobility may be all that is required to achieve efficient redistribution. This case is relevant for optimal redistribution among local governments within a country. As language and culture barriers are becoming less and less relevant as an obstacle for labor mobility in Europe, it may also be more and more relevant for the EU: inter-european redistribution will take place even if it is decentralized and the need for new institutions can be discussed. This conclusion does not hold, however, when individuals face large mobility costs, as may be the case for international migration flows. In these circumstances we have shown that the decentralized solution is inefficient, since it produces suboptimal transfers. Here international institutions have a role to play.

Admittedly, these conclusions rely on a highly stylized model. How robust are our conclusions?

Suppose we had more than one rich region. One could imagine that the optimality of voluntary transfer may be destroyed by a free riding problem. However, this is not the case even with mobility cost. The reason is as follows. As long as the migration cost is the same for all the rich regions,

Suppose we had assumed that less productive agents from the poor region remained such even after moving into the rich region. The contribution of immigrants for the financing of the public good in the rich region would then be smaller, and so the rich region be willing to pay a larger contribution for starving off migration. On the other hand, migration would become less desirable for citizens of region 2, so that a lower transfer would be required to prevent it. Presumably the level of the transfer would 
change, but our main conclusions would not be affected.

More importantly, we have ignored the issue of how inter-regional redistribution and migration interact with intra-regional redistribution (the welfare system). Suppose that not only agents carry their productivity with them when they move, but there is also heterogeneity within each region. If immigrants compete for net subsidies with the poorest in the rich region, now the government in 1 has an alternative tool to reduce migration: it can cut the welfare system. In such a framework a decentralized solution for inter-regional transfers may distort intra-regional redistribution and become inefficient. The interaction between these two levels of redistribution and migration opens up the whole issue of whether,on economic grounds, political rights should be assigned to immigrants. We feel that these are exciting directions for future research.

\section{A Appendix}

\section{A.1 Properties of the migration equilibrium}

We show that $\frac{d\left(W^{1}-W^{2}\right)}{d n}<0$ is equivalent to $(11)$. Differentiating $W(T(\phi, n, e), \phi, n, e)$ with respect to $n$ we get

$$
\frac{d W}{d n}=W_{t} T_{n}+W_{n}
$$

$>$ From the fact that $t$ will be chosen optimally, (the first order condition to (7)), we can apply the envelope theorem so that

$$
\frac{d W}{d n}=W_{n}
$$

and hence

$$
\frac{d\left(W^{1}-W^{2}\right)}{d n}=W_{n}^{1}+W_{n}^{2}
$$


Also, observe that from the indirect utility function in $(6)$, it follows that $\frac{d\left(W^{1}-W^{2}\right)}{d n}<$ 0 iff

$\frac{H_{g}\left(n t_{1}\left(L\left(t_{1}\right)+e_{1}\right)-\phi\right) t_{1}\left(L\left(t_{1}\right)+e_{1}\right)+H_{g}\left((2-n) t_{2}\left(L\left(t_{2}\right)+e_{2}\right)+\phi\right) t_{2}\left(L\left(t_{2}\right)+e_{2}\right)}{2}<\alpha$,

A we observed, in principle, equilibria could entail that one region is vacated and everybody moves into the other region. However, we will exclude this case from consideration. A sufficient condition for this is that in the absence of any transfer, both regions will be populated in period 2 . That is: an $n$ in $(0,2)$ exists solving

$$
W\left(T\left(0, n, e_{1}\right), 0, n, e_{1}\right)=W\left(T\left(0,2-n, e_{2}\right), 0,2-n, e_{2}\right)
$$

Take the simple case where the regions are identical, $e_{1}=e_{2}=e$. Then, from symmetry $n=$ 1 solves (30). In this case the condition is clearly fulfilled. By continuity, we conclude that provided $e_{1}$ and $e_{2}$ are sufficiently close, then migration equilibria will be interior for $\phi=0$. A fortiori, both regions will be populated also if region 1 chooses a positive $\phi$. A positive $\phi$ will mean that more people will live in region 2 . Finally, notice that the inhabitants of region 1 will never choose such a large transfer $\phi$ as to induce vacation of region 1. If this were the case, the effective transfer will be zero - a transfer can only be paid if somebody stays behind and pays. As a result, all individuals would live in region 2 with the low time endowment, and zero transfer. But this is even worse than the situation where only region 1 is populated. Hence, we conclude that if $e_{1}$ and $e_{2}$ are sufficiently close, equilibria will be interior. In the sequel we will only focus on interior stable equilibria.

\section{A.2 Proof of Lemma 1}

Since the subsequent choices of tax rates by the governments of the two regions will be optimal, the envelope theorem implies that all first order effects from changes in tax rates 
vanish. Therefore, we can write the first order condition for $\phi$ as follows:

$$
\left(W^{1}-W^{2}+n W_{n}^{1}-(2-n) W_{n}^{2}\right) N_{\phi}+n W_{\phi}^{1}-(2-n) W_{\phi}^{2}=0
$$

Using (10) this reduces to

$$
N_{\phi}=-\frac{n W_{\phi}^{1}-(2-n) W_{\phi}^{2}}{n W_{n}^{1}-(2-n) W_{n}^{2}} .
$$

Now use (12) to get $\frac{W_{\phi}^{1}}{W_{n}^{1}}=\frac{W_{\phi}^{2}}{W_{n}^{2}}$.

The second order condition to the problem (15) is not trivial, as it involves $N_{\phi \phi}, W_{\phi \phi}^{i}$ and the cross derivatives. However, under the maintained assumption that the migration equilibrium is unique and stable the function $N($.$) is continuous. Therefore the objective$ function of the planner is continuous. Furthermore, we can take the range of possible transfers to be compact $\phi \in[0, \bar{\phi}]$, where $\bar{\phi}$ is some very large number. By Wierstrass theorem the problem (15) then has a solution. It may not be unique, however, generically, it will be. In the sequel we will assume that the solution is unique ${ }^{13}$.

\section{References}

[1] Atkinson, A.B. and J.Stiglitz,(1980), Lectures on Public Economics, New York, McGraw-Hill.

[2] Bottazzi, L. and P.Manasse,(1998),"Bankers' vs Workers' EuropeII: Externalities and Credibility in the EMU", CEPR Working Paper No.

[3] Boadway, R., and F. Flatters, (1992), "Efficiency and equalization payments in a federal system of government:A synthesis and extension of recent rsults", Canadian Journal of Economics, 15, 613-633.

\footnotetext{
${ }^{13}$ The results in the text do not require uniqueness of the solution. When comparing the solutions of different maximization problems, the statements should then be taken as statements about the set of solutions.
} 
[4] Bordignon, M., P.Manasse and G.Tabellini, (1996)," Optimal Regional Redistribution under Asymetric Information", CEPR Discussion Paper No1437

[5] Bucovetsky S., M. Marchand and P. Pestieu (1996),"Tax competition and reveleation of preferences for expenditures", mimeo

[6] Bucovetsky, S. (1998), "Federalism, Equalization and Risk Aversion", Journal of Public Economics, vol 67, pp 301-328.

[7] Cremer, H, V. Forgeaud, M. Leite-Monterio, M. Marchand, P. Pestieau (1997): "'Mobility and Redistribution: a Survey", mimeo.

[8] Dixit, A. and J. Londregan (1997): " Fiscal Federalism and Redistributive Politics", mimeo, Princeton University and UCLA

[9] Epple, D. and T. Romer (1991): "Mobility and Redistribution", Journal of Political Economy, 99, vol 4.

[10] Hercowitz, Z. and D.Pines (1991), "Migration with fiscal Externalities" , Journal of Public Economics, 46, 163-180

[11] Laffont, J.J (1995), "Incentives in China's federal tax system", mimeo, Essex University

[12] Lockwood B. (1996), "Inter-regional insurance with asymmetric information", mimeo,

[13] Myers, G., (1990), Optimality, Free Mobility and Regional Authority in A Federation", Journal of Public Economics, 43, 107-121

[14] Musgrave, R.A. (1959): "The Theory of Public Finance", New York, McGraw-Hill

[15] Oates, W. (1972): "Fiscal Federalism", New York, Harcourt Brace Jovanovich. 
[16] Person, T. and G.Tabellini, (1996a), "Federal Fiscal Constitutions:Risk Sharing and Redistribution", Journal of Political Economy

[17] Person,T. and G.Tabellini,(1996b),"Federal Fiscal Constitutions:Moral Hazard.", Econometrica

[18] Romer, J., (1997): "The (Non-Parochial) Welfare Economics of Immigration", Discussion Paper 97-02, Institute of Economics, Universiry of Copenhagen

[19] Schultz and Sjöström (1997a): "Local Public Goods, Debt and Migration", mimeo, University of Copenhagen

[20] Schultz and Sjöström (1997b): "Elections, Public Debt and Migration", Discussion Paper 1811, Harvard Institute of Economic Research.

[21] Tiebout, C. M. (1956): "A Pure Theory of Local Expenditures", Journal of Political Economy 